International Journal of Information Technology \& Management Information System (IJITMIS)

Volume 10, Issue 1, January-April 2019, pp. 01-10, Article ID: IJITMIS_10_01_001

Available online at

http://www.iaeme.com/IJITMIS/issues.asp? J Type= IJITMIS \& V Type=10\&IType=1

Journal Impact Factor (2016): 8.6217 (Calculated by GISI) www.jifactor.com

ISSN Print: 0976 - 6405 and ISSN Online: $0976-6413$

\title{
UTILISATION AND CHALLENGES OF THE LEARNING MANAGEMENT SYSTEMS IN THE HIGHER EDUCATION INSTITUTIONS IN MALDIVES: THE LECTURERS' AND STUDENTS' PERSPECTIVES
}

\author{
Ibrahim Waheed, Prof. Dr. Andy Seddon \\ Asia Pacific University of Technology \& Innovation (APU), Technology Park, Kuala \\ Lumpur, Malaysia.
}

\begin{abstract}
The purpose of this study is to discover the level of utilisation and challenges in using learning management system (LMS) from the perspective of the lecturers and students in higher education institutions (HEI) in Maldives. This study has examined the utilisation and challenges of LMS in the HEIs in Maldives by conducting a qualitative survey questionnaire with lecturers and students. In this study, three HEIs which are currently using an LMS in Maldives were selected. It was found that the LMSS are utilised for passive communication and they are underutilised for meaningful collaborative teaching and learning. The identified key challenges are the lack of planning and strategies for the LMS implementation, the lack of user participation and training, the need of models to track and forecast the evolution of LMS, and the need to support the decisions regarding LMS implementation. The LMS is at the heart of every successful modern HEI. The failure to implement an effective LMS could affect the success of the HEIs. The HEIs have realised that the failures of the LMS are because of the under-utilisation, lack of planning and strategies, and lack of integration with other information systems. Understanding these issues and challenges is significant for the senior management to take key decisions on implementing LMSs in HEIs to develop a more robust educational ecosystem.
\end{abstract}

Keywords: Learning Management Systems, Educational Technologies, Higher Education, Technology Evolution, LMS.

Cite this Article: Ibrahim Waheed, Prof. Dr. Andy Seddon, Utilisation and Challenges of the Learning Management Systems in the Higher Education Institutions in Maldives: The Lecturers' and Students' Perspectives, International Journal of Information Technology \& Management Information System 10(1), 2018, pp. 01-10. $\mathrm{http}: / /$ iaeme.com/Home/issue/IJITMIS?Volume $=10 \&$ Issue $=1$ 


\section{INTRODUCTION}

The development of Information and Communication Technology (ICT) has impacted several sectors, including the education sector. In other words, the application of LMS is also known as the Course Management System (CMS) which is increasingly prominent in the higher education sector [1].

The educational technology and its applications in the field of higher education have contributed to the development of LMS [2]. Since the implementation of the first LMS in the higher education sector in the 1990s, it has become an essential component to the institutional communication plans, the lecturers' teaching, and the students' learning experiences [3].

Although the LMS plays a major role in the lecturer-student communication at the HEIs, the inconsistencies, the lack of organisation in managing the technical resources, and the lack of integration are some of the serious concerns. It is time for the HEIs to prioritise the coordination, organisation, integration, and interoperability of the LMS, including the supporting technologies for the teaching and learning as one of the core businesses for any HEI.

The three selected HEIs for this study used Moodle and Blackboard Learn LMS platforms. There are various types of available LMS in the form of cloud-based and open source systems from different vendors, such as Absorb, Moodle, Instructure Canvas, Schoology, Blackboard Learn, Edmodo, Quizlet, Google Classroom, and Angel Learning.

The most popular LMSs that are used in the higher education sector are Blackboard Learn, Moodle, and Instructure Canvas. Moodle and Instructure are open sources, while Blackboard is cloud based. Moodle offers a more feasible learning management service which is free, open source and rapidly advancing. Instructure Canvas is a fast-growing LMS with a modern interface and extensive third-party integration. Blackboard Learn is one of the most expensive LMSs in the higher education sector with 18 years of history and countless partnerships [4].

This study investigated the utilisation and the key challenges in using the LMS from the perspective of lecturers and students in HEIs located in Maldives.

Two fundamental research questions are formulated to fulfil the aim of this study as follows: 1) how is the LMS utilised in the HEIs? and 2) what are the key challenges in using the LMS in the HEIs?

The outcome of this research contributes to the future investigation on the factors that affect the evolution of the LMS and the development of the educational technology ecosystem model (ETEM) for the HEIs.

The next section presents the literature review on LMS utilisation and challenges, followed by the methodology of this study. After presenting the key findings, this paper presents a brief discussion of the findings, the limitations, and recommendations for future investigations.

\section{LITERATURE REVIEW}

\subsection{Learning Management System (LMS)}

The learning management system is defined as the driver, facilitating the teaching and learning experience by acting as the central hub for the course management, administration, communication, discussion, the creation of content, storage, and assessment [5]. The LMS has existed since the early 1990s. In the early days, the LMS was designed to be more compatible with the teacher-centric education which was the same as the higher education practice. The higher education has evolved from this concept to a more student-centred teaching and learning by providing more interactive course content [6]. 
Utilisation and Challenges of the Learning Management Systems in the Higher Education Institutions in Maldives: The Lecturers' and Students' Perspectives

\subsection{LMS Utilisation}

\subsubsection{The underutilisation of the existing technologies}

According to the study conducted by Educause [3], it was reported that the vast majority $(85 \%)$ of the lecturers used LMS to enhance their teaching activities. Most of the lecturers used LMS to share the course content and only a few of them used it for interactive educational activities with the students. A total of $47 \%$ of the participants and $56 \%$ of the lecturers said that they rarely use the LMS. There are $31 \%$ of the participants and $37 \%$ of the lecturers who said that they use the LMS on a weekly basis. The majority of the lecturers (58\%) used the LMS to send course-related information to the students and only $41 \%$ of them used it to encourage the interaction with students outside of the classroom. It is argued [3] that the lecturers did not utilise the advanced interactive features of the LMS to enhance the educational experience of the students.

Some elements are related to the purpose of using LMS such as "accessing course content", "submitting course assignments", "checking course progress", "managing assignments", and "receiving feedback on assignments" in the study by Educause [3] which has been reviewed and used in this study to understand the purpose of using LMS in the HEIs in Maldives.

Despite the high percentage of LMS adoption, a few lecturers used its more advanced features [7]. This shows that the LMS is utilised in administrative tasks compared to facilitating the student-centred teaching and learning.

There is the need to improve the technology-based teaching in HEIs where most of the ICT educational technologies such as the LMS is underutilised and not well integrated with other systems [7].

The underutilisation of LMS could be due to the lack of technology awareness and training amongst the lecturers and students. The exclusion of lecturers and students during the implementation of LMS also plays a major role in undermining the use of LMS [5].

\subsection{The Challenges of LMS}

\subsubsection{Analytical models and theories}

The lack of models and theories to analyse the current learning environments and the usage of educational technologies such as LMS is one of the challenges faced by many institutions. The design of the learning experiences in the $21^{\text {st }}$ century will require a theoretical framework and models to guide the study and application of e-learning in the higher education [8]. It is important to adopt this model to provide a better understanding of the institutions' management when making the decisions related to the environment which is described by the model. It also provides the information to forecast the LMS developments, investments, and adoption decisions [8].

\subsubsection{Planning and strategies for the implementation}

The lack of planning and strategies in implementing the educational technologies in HEIs is the key challenge highlighted by the researchers in educational technology. Planning for the appropriate educational technology and integrating it into the LMS will lead to the successful implementation of the LMS for teaching and learning [9].

In order to build the next generation of LMSs, the HEIs must be prepared to focus on crafting the implementation plans, policies, and strategies to provide the solutions for managing the current situation while demonstrating how it can overcome the challenges and 
demands of the future LMS [8]. It is vital to integrate technology planning as a major component of the overall vision and strategy for the HEIs [10].

A study found that the effective implementation of educational technologies such as LMS, a technology-based strategic change, planning, organising, guiding and monitoring of key components of technologies are required for the HEIs [11].

\subsubsection{Technology integration}

The lack of integration of LMS with other supporting technologies can lead to the failure of the management of educational activities in the digital learning environment [12].

A study conducted on over 20 universities worldwide revealed many issues that inhibit the effective integration of technology in the universities [10]. The integration of different tools into LMS posed a challenge. It is believed that the LMS can be integrated with other systems to increase the efficiency of teaching and learning [6].

Integrating technology in the course delivery is vital, and it is important to accept technology investments as the key strategy of the institution [10].

\subsubsection{The Lack of inclusiveness of academics in the implementation}

An LMS will not guarantee the effective use of the technology in the teaching and learning. In order to improve the effectiveness, efficiency, and sustainability of the LMS, it is necessary to engage the academics at the beginning of the implementation process [5].

It is vital for the educators to be involved in the procurement, development, and management of these systems besides interacting and retrieving the information and making decisions. The underutilisation and failure of these systems are due to the decisions made by the ICT department and Chief Information Officer (CIO) [5].

\section{METHODOLOGY}

The data related to the LMS utilisation and challenges were abstracted from an ongoing qualitative research questionnaire conducted for this study.

The rational for conducting an open-ended qualitative questionnaire in this research is to address the two research questions, namely, to understand the LMS utilisation and the key challenges in using LMS in the HEIs in Maldives.

The open-ended questions provide participants with the opportunity to elaborate on their experience of LMS utilisation and the challenges they have faced.

This approach enables more insight to be obtained from the open-ended responses leading to a better understanding of current utilisation of LMSs in Maldives and the challenges faced in HEIs when implementing an LMS. Lecturers and students who are currently using an LMS were included as participants. The researcher randomly selected lecturers and students from three HEIs and potential participants were asked to participate. Participation was voluntary, and anyone could withdraw at any time with no negative repercussions.

The researcher emphasised the voluntary nature of survey participation. Following the completion of the research participants will be provided with a summary of the findings and recommendations for effective implementation of an LMS.

To conduct the survey, the researcher visited all three HEIs to meet with the lecturers and students to distribute the qualitative questionnaires in their respective classes. A briefing about the research and the objective of this qualitative questionnaire was shared with the participants. 
Utilisation and Challenges of the Learning Management Systems in the Higher Education Institutions in Maldives: The Lecturers' and Students' Perspectives

The analysis included the data from 30 lecturers and 45 students from the three different HEIs (HEI1, HEI2, and HEI3) in the Maldives. There were 10 lecturers and 15 students selected from each institution.

The study was conducted using a multiple case study approach to compare the patterns and trends of the lecturers and students in the three HEIs in Maldives that used the LMS.

HEI1 is considered as a large institution, HEI2 as a medium institution, and HEI3 as a small institution. HEI1 and HEI2 used Moodle, and HEI3 used Blackboard Learn which is a franchise partner university LMS (see Table 1).

Table 1 Details of the three Institutions (HEI1, HEI2, and HEI3)

\begin{tabular}{|l|l|l|l|}
\hline Institution & No. of Students & No. of Lecturers & Types of LMS \\
\hline HEI1 & $8,000-8,500$ & $200-250$ & Moodle \\
\hline HEI2 & $1,500-1,800$ & $50-60$ & Moodle \\
\hline HEI3 & $500-700$ & $20-25$ & $\begin{array}{l}\text { Blackboard Learn (Franchise } \\
\text { Partner LMS) }\end{array}$ \\
\hline
\end{tabular}

\section{FINDINGS}

The main objective of this study is to discover the level of utilisation and the challenges in using the LMS from the perspectives of the lecturers and students in the HEIs in Maldives. The preliminary findings reflected the perceptions of the lectures and students on the LMS utilisation and challenges. Figure 1 shows the purpose of using the LMS, Figure 2 shows the percentage of LMS usage, Figure 3 shows the aspects of the LMS satisfaction, and Figure 4 shows the challenges faced by the HEIs in using LMS from the perspectives of the lecturers and students.

\subsection{LMS Utilisation}

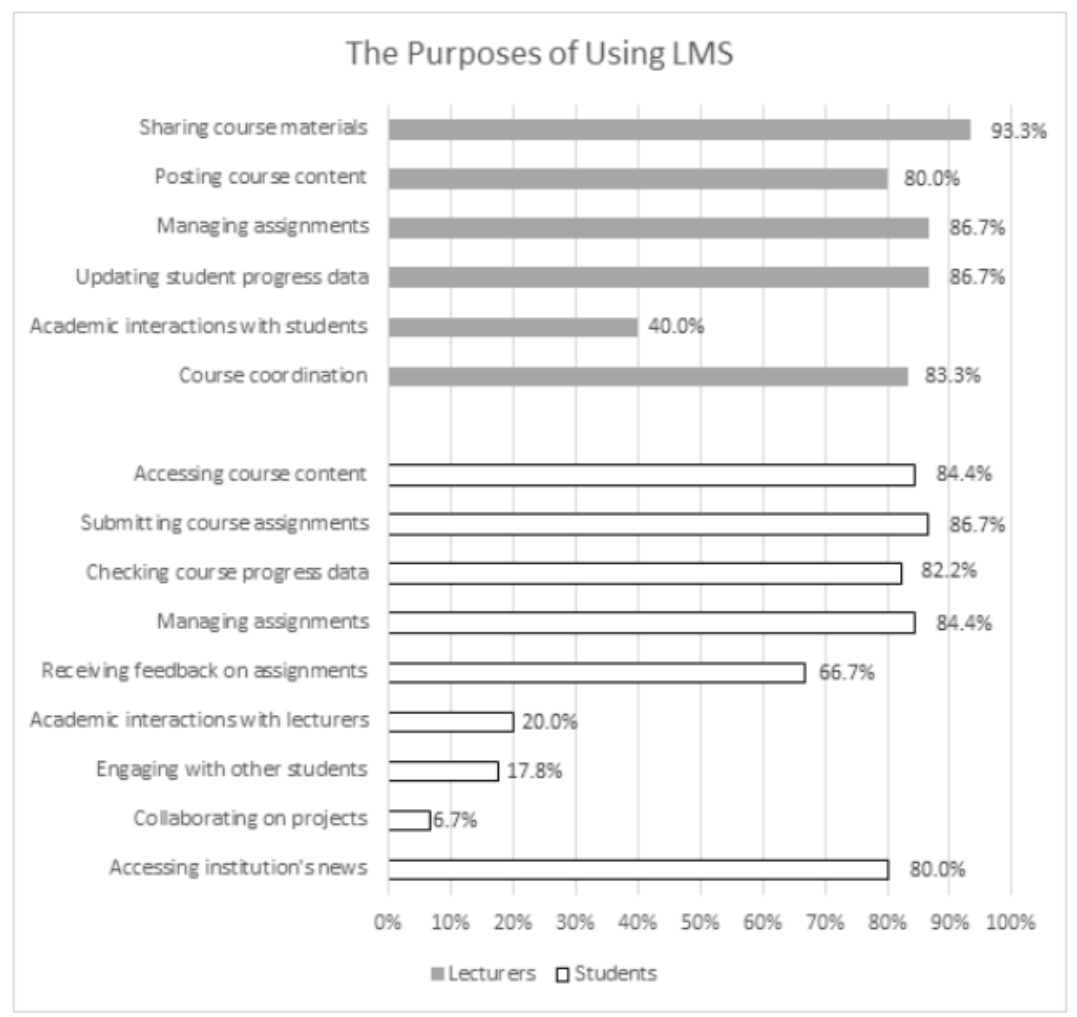

Figure 1 The Purposes of using LMS 
Most of the lecturers (93.3\%) stated that they use the LMS for sharing the course materials, whereas the majority of the students $(86.7 \%)$ stated that they use the LMS for submitting their course assignments. The results show that most of the lecturers use the LMS for managing assignments (86.7\%), course coordination $(83.3 \%)$, posting course content $(80 \%)$, and updating student progress data $(86.7 \%)$. However, $40 \%$ of the lecturers use the LMS for academic interactions with students, whereas $20 \%$ of the students said that they use the LMS for academic interactions with the lecturers. The second highest percentage for the use of the LMS by the students are accessing course content (84.4\%) and managing assignments $(84.4 \%)$, followed by checking course progress data $(82.2 \%)$. The majority of the students agreed that they use the LMS to access their institution's news (80\%) and receive feedback on assignments $(66.7 \%)$, whereas only $17.8 \%$ of the students said that they use the LMS to engage with other students, and only $6.7 \%$ of them use the LMS for collaborating on projects. These results (Figure 1) found that the students and lectures did not use the most advanced functionalities of the LMS and the LMS is widely used for passive communication only.

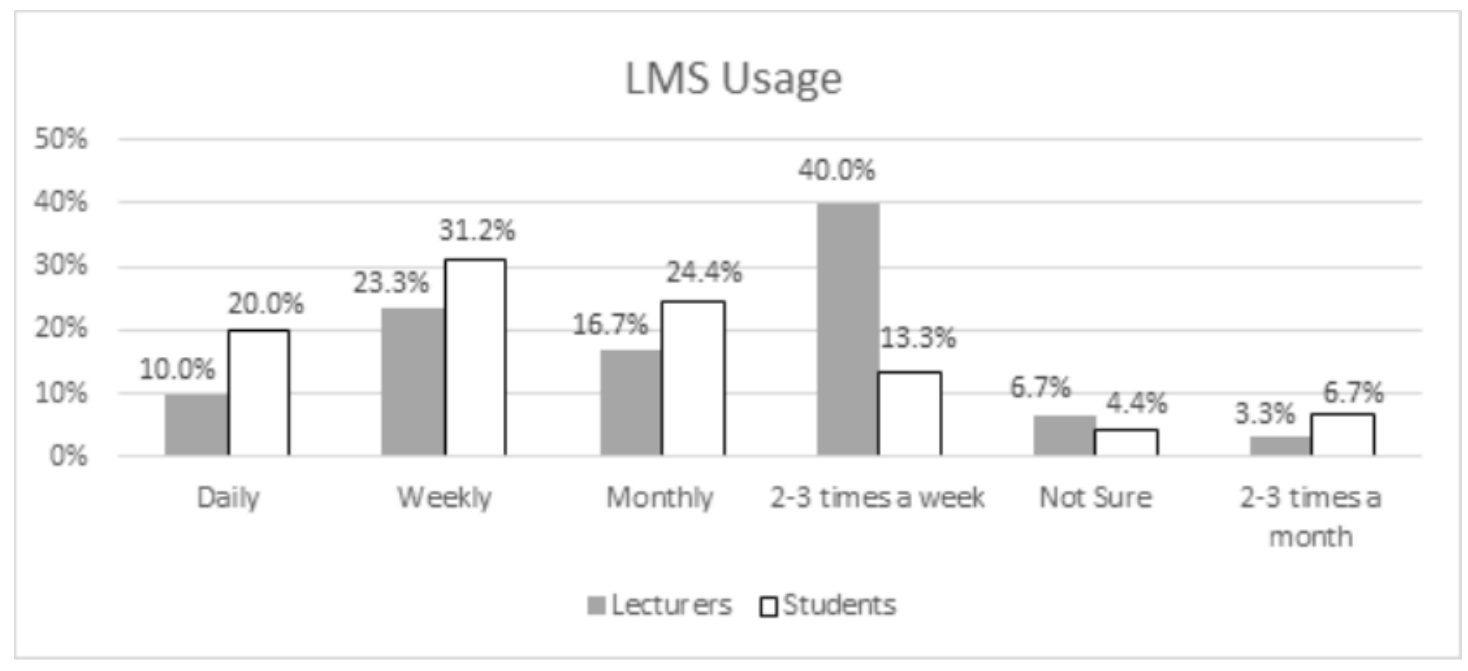

Figure 2 LMS Usage

From the lecturers' perspectives, most of them (40\%) agreed that they use the LMS about two to three times a week, $23.3 \%$ of them use the LMS on a weekly basis, and $16.7 \%$ use LMS on a monthly basis. Only $10 \%$ of the lecturers said that they use the LMS on a daily basis, whereas $3.3 \%$ of the lecturers use the LMS about two to three times a month. A total of $6.7 \%$ of the lecturers are not sure about their LMS usage. From the students' perspectives, most of the students said that they use the LMS on a weekly (31.2\%), daily (20\%), and monthly basis $(24.4 \%)$. However, $4.4 \%$ of them said that they are not sure about the LMS usage. In contrast with the lecturers, $13.3 \%$ of the students use the LMS about two to three times a week, whereas $10 \%$ of them use the LMS about two to three times a month. Only $6.7 \%$ of the students use the LMS about two to three times a month.

The above data (Figure 2) shows that the LMS is underutilised because most of the lecturers and students use the LMS for sharing course contents, managing assignments, and managing courses (Figure 1) that do not require the frequent use of LMS. It is interesting that all of the lecturers who use the LMS for academic interactions with their students $(40 \%)$ use the LMS about two to three times a week, whereas the students who use LMS for academic interactions with their lecturers $(20 \%)$ use the LMS on a daily basis. It can be said that the respondents who are more engaged and interactive, use the LMS more frequently than those who use it to support teaching and learning. 
Utilisation and Challenges of the Learning Management Systems in the Higher Education Institutions in Maldives: The Lecturers' and Students' Perspectives

\subsection{LMS Satisfaction Related to System Features}

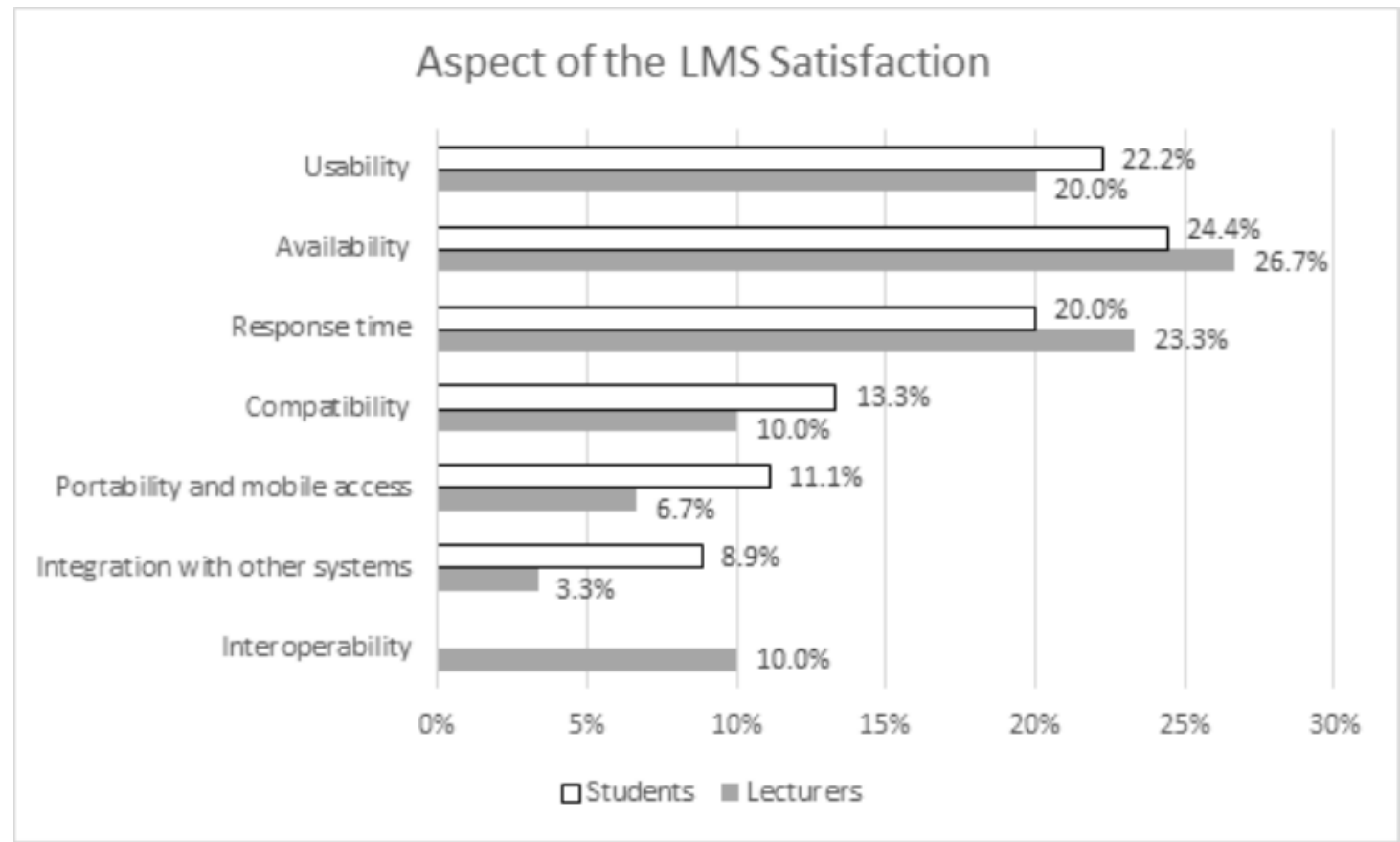

Figure 3 Aspect of the LMS Satisfaction

Most of the lecturers (26.7\%) said that the availability of the system contributes to the highest aspect of LMS satisfaction, while $24.4 \%$ of the students are happy with the availability of the system. A total of $23.3 \%$ lecturers ranked the response time as the second highest aspect of LMS satisfaction, whereas the students have a total percentage of $17.8 \%$. The students ranked usability as the second highest aspect of LMS satisfaction $(22.2 \%)$, which is similar with the lecturers' ranking for this aspect in the third place $(20 \%)$.

Compatibility (10\%) and interoperability (10\%) shared the fourth rank among the lecturers. In contrast, no student believed that interoperability plays any role in LMS satisfaction. Only $6.7 \%$ of the lecturers stated that portability and mobile access as the aspect of the LMS satisfaction and $11.1 \%$ of the students who have the same opinion. In a very similar pattern, only $3.3 \%$ of the lecturers said that the integration with other system is the key aspect of the LMS satisfaction compared with the students' percentage of $8.9 \%$.

The satisfaction aspect of integration with other systems has yielded the lowest percentage (3.3\%) followed by portability and mobile access (6.7\%) among the lecturers. In a similar pattern, the students perceived LMS integration with other systems $(8.9 \%)$ as the least aspect of LMS satisfaction followed by portability and mobile access $(11.1 \%)$.

Figure 3 reveals the issue of LMS integration with other educational technologies in the HEIs in Maldives which is in line with the literature. 


\subsection{Key Challenges of LMS}

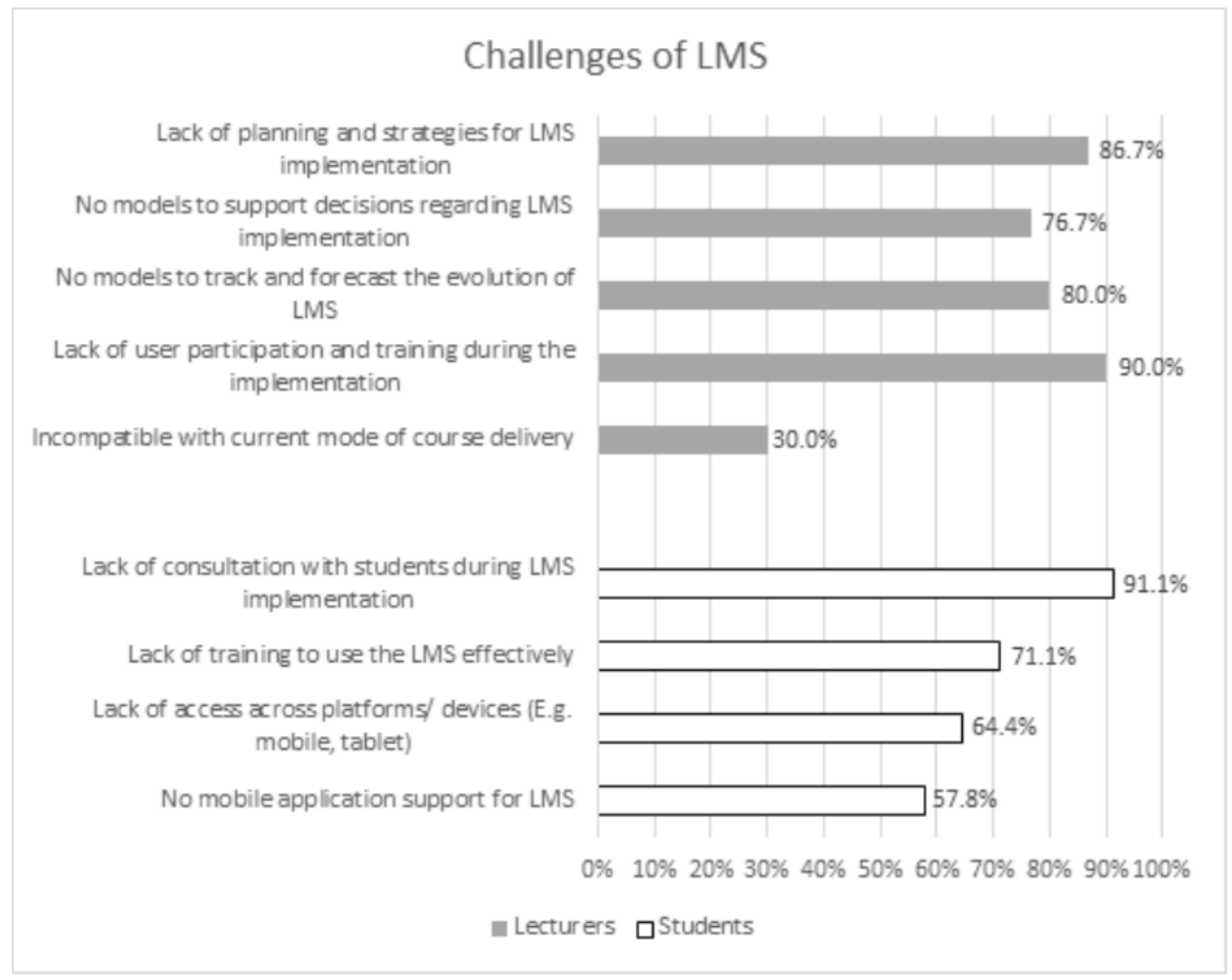

Figure 4 Challenges of LMS

Most of the lecturers (90\%) recognised the lack of user participation and training during the implementation as the main challenge, while majority of the students $(91.1 \%)$ said that the lack of consultation with students during LMS implementation is the main challenge for the effective implementation of LMS. Other challenges highlighted by the lecturers are the lack of planning and strategies for the LMS implementation $(86.7 \%)$, no models to track and forecast the evolution of LMS (80\%), and no models to support decisions regarding the LMS implementation (76.7\%). There were only $30 \%$ of the lecturers who said that the incompatibility of the LMS with the current mode of delivery is a challenge. The second most highlighted challenges when using LMS by the students are the lack of training to use the LMS effectively (71.1\%), the lack of access across platforms or devices $(64.4 \%)$, and no mobile application support for the LMS (57.8\%).

The lecturers $(30 \%)$ stated that the incompatibility of LMS with the current modes of course delivery is a challenge when using the LMS. The incompatibility with the modes of delivery was not identified as a challenge in the literature review. It might be due to the restrictions of the full course delivery through LMS platforms in the HEIs in Maldives.

Figure 4 shows the urgency of communally addressing these challenges which must be at the heart of any successful implementation of the LMS.

\section{DISCUSSION}


According to the findings presented in this study, almost all of the utilisation issues and challenges of implementing and managing LMS in the HEIs in Maldives are in line with the literature review. These issues include underutilisation, the lack of training, integration, and participation during LMS development and implementation. These issues can be addressed with appropriate planning and integrating strategies when implementing the LMS. If these issues and challenges can be identified and addressed during the implementation phase, the efficient LMS has a high possibility of being accepted by all stakeholders.

A total of $40 \%$ lecturers revealed that they used LMS for academic interaction with the students (Figure 1). The distributions are as follows: 50\% of them are from HEI2, 33.3\% from HEI3, and $16.7 \%$ from HEI1. It was found that the HEIs that used their partner's LMS tend to have lower usage than those who used their own LMS. A similar trend was observed from the students' perspectives as $20 \%$ of them said that they used the LMS for academic interaction with lecturers (Figure 1), and $11 \%$ of them who were from the institutions that used the partner's LMS. None of them used the LMS for engaging with other students and collaborating on projects which may indicate that it is optional for them to use the LMS for collaborative learning.

The data suggested that there was no relation between the aspects of LMS satisfaction and the type of LMS that they were using for teaching and learning. A percentage of $10 \%$ lecturers said that compatibility is the feature contributing to their satisfaction (Figure 3), and all three institutions agreed with the statement. However, there was no respondent who used the Blackboard Learn that considered the two aspects of portability and mobile access and integration with other systems as the features that contributed to LMS satisfaction. None of the respondents from HEI2 who used Moodle agreed that LMS integration with other systems is the key aspect of the LMS satisfaction.

There is no meaningful difference in the challenges when using LMS among the three different institutions. The findings revealed similar challenges in the three institutions, except for one challenge which was highlighted by the respondents who are from HEI3 that used their partner's LMS. A total of 30\% lecturers said that the incompatibility of LMS with the current mode of course delivery is the key challenge (Figure 4), 55.6\% of the lecturers are from HEI3, 11.1\% from HEI1, and 33.3\% from HEI2. It is believed that the institution that used the partner's LMS faced more challenges in running the courses using the local course delivery mode.

The challenge must be addressed to enable more advanced aspects of learning such as interactive, student-centred collaborative teaching and learning to extend and enhance the use of LMSs.

\section{CONCLUSION}

This study revealed that using the LMS in teaching and learning, in the HEIs in Maldives is more focused on the passive aspects of learning because the LMS components are frequently used for assignment management, course management, course content sharing, and information sharing. This study has identified the strategies for effective implementation of LMS which are; better strategic planning, models to support key decisions, models to track and forecast the evolution of the LMS, user involvement and training during implementation, streamlining the course delivery to make it more compatible with the LMS, and better integration and interoperability. Due to the global surge of using LMS for teaching and learning in HEIs, the success depends on the efficient and effective system that meets the stakeholders' expectations (integrated, portable, mobile friendly, interoperable, evolving, 
stakeholder inclusive development and implementation, and proper training) and institutional standards (full utilisation and acceptance).

This study only addressed LMS utilisation and challenges with the perspectives of lecturers and students. The future research will investigate the underutilisation of a partner university LMS by comparing it with a local LMS, and the aspects of satisfaction between a cloud-based LMS and an open source LMS. It is suggested that several areas should be investigated in the future research such as the success of LMS implementation as well as the challenges of implementing an LMS for conventional modes of course delivery. One such area of investigation is to understand the issues and challenges from the perspectives of CIOs and senior academics in the HEIs in Maldives.

Overall, it can be concluded that the outcome of this research contributes to the future investigation on the factors affecting the evolution of the LMS and the development of an educational technology ecosystem model (ETEM) for the HEIs in Maldives.

\section{REFERENCES}

[1] Vermaat, M. E., Sebok, S. L., Freund, S. M., Campbell, J. T., and Frydenberg, M. Discovering Computers 2016. Singapore: Cengage Learning, 2016.

[2] Abdallah, N. A. O., Ahlan, A. R., and Abdullah, O. A. Factors Affecting Instructors' Adoption of Learning Management Systems: A Theoretical Framework, Proceedings $6^{\text {th }}$ International Conference on Information and Communication Technology for The Muslim World, Jakarta, 2016, pp. 13-18.

[3] Dahlstrom, E., Brooks, D. C., and Bichsel, J. The Current Ecosystem of Learning Management Systems in Higher Education: Student, Faculty, and IT Perspectives. Educause, 2014. http://www.educause.edu/ecar.

[4] Fenton, W., The Best (LMS) Learning Management Systems for 2018, 2018. http://sea.pcmag.com/absorb-lms/10984.

[5] Lang, L. and Pirani, J. A. The Learning Management System Evolution, Educause, 2014. https://library.educause.edu/resources/2014/5the-learning-management-system-evolution

[6] Brown, M., Dehoney, J., and Millichap, N., What's Next for the LMS?, 2015. http://er.educause.edu/articles/2015/6/whats-next-for-the-lms.

[7] Brown, M., Dehoney, J., and Millichap, N. The Next Generation Digital Learning Environment, 2015. https://ibrary.educause.edu/ /media/files/library/2015/4/eli3035-pdf.pdf.

[8] Garrison, D. R., E-Learning in the 21st Century: A Community of Inquiry Framework for Research and Practice, $3^{\text {rd }}$ Edition. UK: Routledge, 2016.

[9] Lever-Duffy, J. and McDonald, J. Teaching and Learning with Technology, 5th Edition. USA: Pearson Education, 2015.

[10] Bates, A. W. and Sangra, A. Managing Technology in Higher Education: Strategies for Transforming Teaching and Learning. San Francisco: John Wiley \& Sons, 2011.

[11] S. Ghavifekr and S. Hussin. Managing Systemic Change in a Technology-Based Education System: A Malaysian Case Study. Procedia- Social and Behavioral Sciences, Nicosia/Kyrenia, 2011, pp. 455-464.

[12] L. Morgado et al., Integrating Virtual Worlds with Learning Management Systems: The MULTIS Approach. Proceedings $15^{\text {th }}$ International Conference on Ubiquitous Computing and Communications, 2016, pp. 167-172. 